\title{
LABORATORY TOXICITY OF MOSQUITO ADULTICIDES TO THE ASIAN TIGER MOSQUITOES, AEDES ALBOPICTUS AND THE HONEY BEES, APIS MELLIFERA
}

\author{
HUSSEIN SANCHEZ-ARROYO', ROBERTO M. PEREIRA, \\ YONG-XING JIANG ${ }^{2}$, DANIEL DIXON ${ }^{3,4}$ RUI-DE XUE ${ }^{3}$, \\ AND PHILIP G. KOEHLER \\ 'Colegio de Postgraduados, México
}

${ }^{2}$ Gainesville Mosquito Control, 405 NW 39th Ave. Gainesville, FL 32609

${ }^{3}$ Anastasia Mosquito Control District, 120 EOC Drive, St. Augustine, FL 32092

${ }^{4}$ Current address: USDA/CMAVE, 1600 SW 23rd Dr., Gainesville, FL 32608

Guest editor: Vindhya S. Aryaprema

\begin{abstract}
Aedes albopictus and Apis mellifera were exposed to six insecticide active ingredients and five commercial insecticide formulations by topical application and insecticide-impregnated paper strips respectively to determine the differential toxicity and the potential use of the two methods in insecticide resistance monitoring surveys. By topical application deltamethrin was the most toxic active ingredient $\left(\mathrm{LD}_{50}=0.018 \mu \mathrm{g} / \mathrm{g}\right)$ for Ae. albopictus whereas chlorpyrifos was the least toxic $\left(\mathrm{LD}_{50}=0.499 \mu \mathrm{g} / \mathrm{g}\right)$. For Apis mellifera, the most toxic active ingredients were bifenthrin $\left(\mathrm{LD}_{50}=0.047 \mu \mathrm{g} / \mathrm{g}\right)$ and deltamethrin $\left(\mathrm{LD}_{50}=0.055 \mu \mathrm{g} / \mathrm{g}\right)$ while chlorpyrifos $\left(\mathrm{LD}_{50}=0.215 \mu \mathrm{g} / \mathrm{g}\right)$ and permethrin $\left(\mathrm{LD}_{50}=0.287 \mu \mathrm{g} / \mathrm{g}\right) \mathrm{had}$ comparatively low toxicity. When the insecticide-impregnated method was used, Mosquito Mist (a.i. chlorpyrifos) was the most toxic commercial formulation for both Ae. albopictus $\left(\mathrm{LC}_{50}=0.028 \mu \mathrm{g} / \mathrm{cm}^{2}\right)$ and A. mellifera $\left(\mathrm{LC}_{50}=0.059 \mu \mathrm{g} /\right.$ $\left.\mathrm{cm}^{2}\right)$. Duet and DeltaGard showed the least toxicity $\left(\mathrm{LC}_{50}=2.429 \mu \mathrm{g} / \mathrm{cm}^{2}\right.$ and $\mathrm{LC}_{50}=0.491 \mu \mathrm{g} / \mathrm{cm} 2$ respectively) for $A e$. albopictus and DeltaGard was the least toxic to A. mellifera $\left(\mathrm{LC}_{50}=18.09 \mu \mathrm{g} / \mathrm{cm}^{2}\right)$.

When using the topical application method with insecticide active ingredients, more than 3 times permethrin and deltamethrin were required to obtain the same mortality rate in A. mellifera as in Ae. albopictus. However, chlorpyrifos was more toxic for A. mellifera than for Ae. albopictus. In the insecticide-impregnated paper-strip method with commercial insecticide formulations, more than 36 times of DeltaGard was required to obtain the same mortality rate in A. mellifera as in Ae. albopictus. Even though the Mosquito Mist is the most toxic commercial formulation for both insect species, A. mellifera were more than 2 times tolerant to this insecticide compared to Ae. albopictus.

The study concludes the active ingredient deltamethrin or its commercial formulation DeltaGard is the best among tested insecticides to control Ae. albopictus with minimal effects to A. mellifera.
\end{abstract}

Key Words: Aedes albopictus, Apis mellifera, insecticides, toxicity, mosquito control

\section{INTRODUCTION}

Aedes albopictus Skuse, also called as the Asian tiger mosquito is a widely distributed mosquito species in tropical, subtropical and temperate climate zones. It is an important vector of several viral infections, including yellow fever, dengue, chikungunya, and Zika virus. The spraying of chemical insecticides to control the vector is one of the most important methods to prevent the transmission of those arboviral diseases. Pyrethroids have been widely used as indoor/outdoor residual or space sprays for mosquito control because of their high effectiveness. Usage of some insecticides results in unfortunate consequences to nontarget beneficial organisms such as honeybees.

Honeybees are responsible for providing more than $90 \%$ of commercial pollination services in agricultural crops in United States (Bruckner et al. 2019). The elevated loss rates seen recently in managed honeybee colonies threaten those pollination ser- 
vices (Lopez-Uribe and Simone-Finstrom, 2019). Therefore, there is a global concern about the decline of honeybee populations which is attributed to a range of factors such as "Colony Collapse Disorder" (Williams et al. 2010), pathogens and pesticides (Ostiguy et al. 2019). Since the worker honeybees can forage up to $12 \mathrm{~km}$ around their hive and reach urban areas (Beekman and Ratnieks 2000), they can be exposed to a several different insecticides. Some studies have concluded that barrier or ground insecticide applications to control host-seeking mosquitoes may affect nontarget insects such as honeybees (Qualls et al. 2010; Drake et al. 2016). Better practices should be adhered to minimize adverse effects on non-target organisms such as honeybees while implementing mosquito control with insecticides.

Increased use of insecticides leads to the progressive development of chemical insecticide resistance among mosquitoes (Knox et al. 2014) and therefore, programs using insecticides to control mosquitoes should always include insecticide resistance monitoring and management. Standard laboratory studies utilize topical bioassays, applying insecticides to the mesothoracic pleural or dorsal body regions, or the use of insecticide-impregnated papers, where insects pick up chemical on their tarsi. Both of these methods are commonly used to determine toxicity or insecticide resistance (WHO, 2009, WHO, 2018).

The objectives of this study were to determine the differential toxicity of six active ingredients and five commercial insecticide formulations on Ae. albopictus and Apis mellifera using two bioassay methods and determine their potential use in future insecticide resistance monitoring surveys. It would help mosquito control personnel to make informed decisions on the best use of insecticides that will have minimum to no effect on honeybee populations.

\section{MATERIALS AND METHODS}

Insects. Ae. albopictus adults were obtained from colonies maintained at the USDA-ARS, Center for Medical, Agricul- tural, and Veterinary Entomology (CMAVE) in Gainesville, FL., USA. A. mellifera were obtained from an apiary managed by the Honey Bee Research and Extension Laboratory, Entomology and Nematology Department, University of Florida, Gainesville, FL., USA. Mosquitoes and honeybees were provided with $10 \%$ and $50 \%$ sucrose solution ad libitum respectively throughout the experiments. The honeybee colonies were of mixed race, European-derived stock housed in standard Langstroth-style equipment and managed according to common practices for North Central Florida.

Active ingredient experiments. Six commonly used mosquito adulticidal active ingredients namely, phenothrin $(94.6 \%)$, prallehtin $(96 \%)$, deltamethrin $(99.7 \%)$, chlorpyrifos $(99.3 \%)$, permethrin $(96.7 \%)$ and bifenthrin $(99.1 \%)$ from Sigma-Aldrich, USA were used in the experiments. The active ingredients were serial-diluted in acetone to make $1.0,0.1,0.01,0.001,0.0001$, and $0.00001 \%$ dilutions. In the second part of the bioassay intermediate dilutions were included. Each dilution was applied separately on thoraxes of Ae. albopictus and $A$. mellifera adult females by topical application method. Ten adult female mosquitoes (3-4 days old) were knocked down exposing to $\mathrm{CO}_{2}$ for $15 \mathrm{~s}$ for each of the 5 replicates per treatment and treated with $0.1 \mu \mathrm{l}$ of an insecticide preparation using a $5 \mu$ l syringe (Hamilton Co. Reno NV) and a repeating dispenser (Hamilton PB 600-1). Treated mosquitoes were transferred to $20-\mathrm{ml}$ scintillation vials and covered with a mesh to prevent escape. The mosquitoes of control experiments were treated with acetone only.

Ten adult worker $A$. mellifera (5-10 days old) were knocked down with $\mathrm{CO}_{2}$ for $20 \mathrm{~s}$ for each of 5-7 replicates per treatment and treated with $1 \mu \mathrm{l}$ of the insecticide preparation using a $50 \mu \mathrm{l}$ syringe (Hamilton Co. Reno NV) and a repeating dispenser (Hamilton PB 600-1). They were then transferred to $120-\mathrm{ml}$ glass jars and covered with a mesh. The honeybees of control experiments were treated with acetone only.

Commercial insecticide experiments. Five commercial insecticides; Mosquito Mist 
(chlorpyrifos 24.6\%), Aqualuer (permethrin $20.6 \%$, PBO 20.6\%), DeltaGard (deltamethrin $2.0 \%$ ), Duet (Prallethrin $1.0 \%+$ Phenothrin 5.0\%) and Talstar (Bifenthrin $7.9 \%$ ) were tested using the insecticide-impregnated paper method. Serial dilutions were prepared using different diluents depending of the pesticide formulation. Mosquito Mist and Aqualuer were diluted in acetone; DeltaGard and Talstar were diluted in distilled water; and Duet was diluted in mineral oil. The diluent for the control experiments was the same for the corresponding insecticide. Different amounts of insecticide solution were applied depending on the solvent used for each commercial formulation.

Each insecticide preparation was applied to filter paper strips (Whatman filter paper \# 2). For A. mellifera the strips were $14 \mathrm{~cm}^{2}(2 \times 7 \mathrm{~cm})$ and for Ae. albopictus the strips were $5 \mathrm{~cm}^{2}(1 \times 5 \mathrm{~cm})$. Dosages of insecticides were calculated as such to ensure the same amount of insecticides per $\mathrm{cm}^{2}$ in both sizes of the paper strips (Table 1).

Ten adult Ae. albopictus females (3-4 days old) were knocked down using $\mathrm{CO}_{2}$ for $15 \mathrm{~s}$ for the replicate of each concentration and transferred to 20-ml scintillation vials with mesh covers. After 30 minutes and complete recovery from $\mathrm{CO}_{2}$ anesthetizing, the insecticide-impregnated paper strip was introduced to the scintillation vial. Five replicates were carried out on separated days.

Ten worker A. mellifera (5-10 days old) were knocked down using $\mathrm{CO}_{2}$ for $20 \mathrm{~s}$ for the replicate of each concentration and transferred to a 120-ml glass jars with mesh covers. After 30 minutes and complete recovery from $\mathrm{CO}_{2}$ anesthetizing, the insecticideimpregnated strip was introduced to the jar.

Table 1. Amounts of different insecticides used to impregnated the paper strips.

Amounts used $(\mu \mathrm{l})$

\begin{tabular}{lcc} 
Insecticide & Ae. albopictus & A. mellifera \\
\hline Mosquito Mist & 32 & 90 \\
AquaLure & 32 & 90 \\
DeltaGard & 50 & 140 \\
Talstar & 50 & 140 \\
Duet & 25 & 70 \\
\hline
\end{tabular}

Any bees that were not walking at the time the insecticide-treated paper strip was added to the jars were not considered for the experiment. Five to seven replicates were carried out on separated days.

At least 350 each of Ae. albopictus and A. mellifera ( 50 control and 300 insecticide treated) were tested for mortality against each insecticide in each experiment. Mortality was assessed $24 \mathrm{~h}$ post exposure to insecticides. When mortality in control experiments were above $5 \%$, mortality data of corresponding treatment experiments were corrected using Abbott's (1925) formula before calculating $\mathrm{LD}_{50}$ or $\mathrm{LC}_{50} . \mathrm{LD}_{50}$ or $\mathrm{LC}_{50}$ values were compared to determine the differential toxicity of insecticides to the two species. Data were analyzed by probit analysis and significance was assessed by the degree of overlap of $95 \%$ CI (SAS 9.4 Institute Inc., Cary, NC).

\section{RESULTS}

Toxicity of the active ingredients. Deltamethrin was the most toxic $\left(\mathrm{LD}_{50}=0.018\right.$ $\mu \mathrm{g} / \mathrm{g})$ among the 6 tested adulticidal active ingredients when applied topically on $\mathrm{Ae}$. al bopictus followed by bifenthrin $\left(\mathrm{LD}_{50}=0.029\right.$ $\mu \mathrm{g} / \mathrm{g})$, permethrin $\left(\mathrm{LD}_{50}=0.076 \mu \mathrm{g} / \mathrm{g}\right)(\mathrm{Ta}-$ ble 2). Chlorpyrifos was the least toxic active ingredient $\left(\mathrm{LD}_{50}=0.499 \mu \mathrm{g} / \mathrm{g}\right)$ for this mosquito species.

For A. mellifera, the most toxic insecticides were bifenthrin $\left(\mathrm{LD}_{50}=0.047 \mu \mathrm{g} / \mathrm{g}\right)$ and deltamethrin $\left(\mathrm{LD}_{50}=0.055 \mu \mathrm{g} / \mathrm{g}\right)$, with no significant differences between them, followed by phenothrin $\left(\mathrm{LD}_{50}=0.131 \mu \mathrm{g} / \mathrm{g}\right)$. The least toxic active ingredient for $A$. mellifera was prallethrin $\left(\mathrm{LD}_{50}=0.779 \mu \mathrm{g} / \mathrm{g}\right)$ which is normally added to commercial formulations only to produce the knockdown effect because of its low toxicity. Chlorpyrifos $\left(\mathrm{LD}_{50}=0.215 \mu \mathrm{g} / \mathrm{g}\right)$, permethrin $\left(\mathrm{LD}_{50}=\right.$ $0.287 \mu \mathrm{g} / \mathrm{g}$ ) had low toxicity to A. mellifera. Both insect species had similar susceptibility to phenothrin, with $\mathrm{LD}_{50 \text { 's }}$ of $0.186 \mu \mathrm{g} / \mathrm{g}$ for Ae. albopictus and $0.131 \mu \mathrm{g} / \mathrm{g}$ for A. mellifera.

A. mellifera were 3.78X, 3.06X, and 3.04X more tolerant to permethrin, deltamethrin and prallethrin respectively compared to Ae. albopictus (Table 2) when using topi- 
cal applications. However, chlorpyrifos and phenothrin were more toxic $(2.32 \mathrm{X}, 1.41 \mathrm{X}$ respectively) for $A$. mellifera than for Ae. albopictus.

Toxicity of commercial insecticides. Mosquito Mist (a.i. chlorpyrifos) was the most toxic among 5 tested commercial insecticides for Ae. albopictus with $\mathrm{LC}_{50}=0.028$ $\mu \mathrm{g} / \mathrm{cm}^{2}$ followed by Talstar and Aqualuer. Duet was the least toxic insecticide $\left(\mathrm{LC}_{50}=\right.$ $2.429 \mu \mathrm{g} / \mathrm{cm}^{2}$ ) (Table 3 ). The most toxic commercial insecticide for A. mellifera also was the Mosquito Mist $\left(\mathrm{LC}_{50}=0.059 \mathrm{~cm}^{2}\right)$ followed by Talstar $\left(\mathrm{LC}_{50}=0.243 \mathrm{~cm}^{2}\right)$. The least toxic commercial insecticide was DeltaGard $\left(\mathrm{LC}_{50}=18.09 \mu \mathrm{g} / \mathrm{cm}^{2}\right)$. No toxicity differences were noted between A. mellifera and Ae. albopictus for Talstar and Duet (Table 3).

Different insect behaviors were noted during the experiment depending on the insecticide used for paper impregnation. Both insect species walked for shorts periods of time onto the pyrethroid-impregnated papers; apparently trying to avoid them. This behavior was not observed when the insects were exposed to chlorpyrifos. It indicates that they were exposed to chlorpyrifos for longer periods of time compared with pyrethroids. This might have attributed to the higher toxicity for Chlorpyrifos compared to pyrethroid insecticides.

A. mellifera was $36.84 \mathrm{X}$ more tolerant to DeltaGard compared to Ae. albopictus. Even though Mosquito Mist is the most toxic insecticide for both insect species, A. mellifera was $2 \mathrm{X}$ more tolerant (Table 3 ).

\section{DISCUSSION}

The present study determines the deferential toxicity of six insecticide active ingredients and five commercial formulations on Ae. albopictus and A. mellifera. Results indicate that all the pyrethroid active ingredients were more toxic to Ae. albopictus than organophosphate chlorpyrifos. However, chlorpyrifos was more toxic for A. mellifera than permethrin and prallethrin. Among the commercial insecticide formulations Mosquito Mist, the one with the active ingredient chlorpyrifos, was the most toxic for

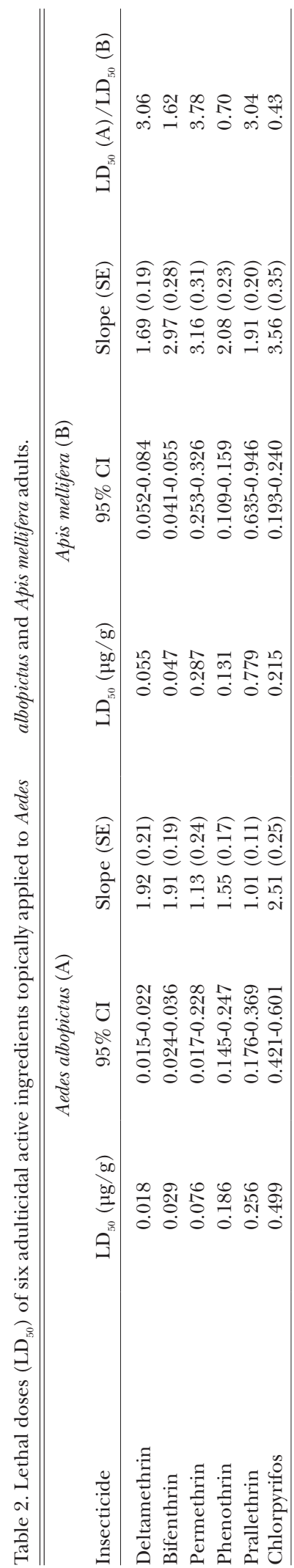


both species. One possible reason for evidenced lower toxicity of pyrethroid insecticides, when exposed to impregnated paper strips, could be the irritation they produce being kept the insects from getting in touch with the paper strips for a period longer enough to pick up the insecticide. Since, chlorpyrifos does not causes irritation the insects move freely around the insecticideimpregnated papers until they get a lethal dose.

The insecticide-impregnated paper method was originally developed to evaluate discriminating doses. In this method, the more the exposed insects move on the paper the more insecticide they pick up by their tarsi. Additionally, it has been reported that the insecticide applied to the mosquito tarsomeres of the hind leg spread out across all the tarsomeres, the tibia, and a portion of the femur of the hind leg (Aldridge et al. 2016). Both permethrin (pyrethroid) and malathion (organophosphate) contacted through appendages such as the leg has resulted in much lower mortality (Aldridge et al. 2016). Unlike in the insecticide -impregnated paper method, the topical application allows the direct absorption of applied insecticide and therefore more appropriate for the determination of toxicity of pyrethroid insecticides.

On that basis, among the tested insecticides, deltamethrin or the commercial formulation DeltaGard would be the best for controlling Ae. albopictus with minimal effects on A. mellifera. However, Mosquito Mist, the commercial formulation of chlorpyrifos and Aqualuer, the commercial formulation of permethrin, would be considered as optional insecticides for resistance management. Previous studies have reported $\mathrm{LD}_{50}$ $0.59 \mu \mathrm{g} / \mathrm{g}$ (Greig-Smith et al. 1994) and $\mathrm{LD}_{50}$ range from 0.59 to $1.14 \mu \mathrm{g} / \mathrm{g}$ (Hardsome and Scott 2010) of chlorpyrifos for honeybees which are very similar to those reported in the present study $\left(\mathrm{LD}_{50} 0.499 \mu \mathrm{g} / \mathrm{g}\right)$. Previously reported $\mathrm{LD}_{50}$ values of permethrin for honeybees are $1 \mu \mathrm{g} / \mathrm{g}$ (Inglesfield, 1989) and $0.15 \mu \mathrm{g} / \mathrm{g}$ (Danka 1986). Compromisingly, our study reports an intermediate value of $\mathrm{LD}_{50}$ of $0.287 \mu \mathrm{g} / \mathrm{g}$. 
Considering that pyrethroids are the most common insecticides used for adult mosquito control, and the honeybees are moderately sensitive to deltamethrin and permethrin (Hardstone and Scott 2010), Al-Naggar et al. (2015) suggested that the application of these insecticides when pollinators are not foraging is an important step in avoiding unnecessary exposure of bees. Correct application timing combined with better insecticide application techniques can further increase safety of mosquito adulticidal applications on non-target insects. Aerial ultra-low volume applications using high-pressure nozzle system reduces environmental insecticides contamination and lead to decreased bee mortality (Zhong et al. 2004). Similar studies can lead to improved application techniques that can be used in the control of mosquitoes in the field with lower risk for honeybees.

Atkins et al. (1973 and 1975, cited by Danka et al. 1986) reported that the majority of referenced insecticide results are topical or contact, and the $\mathrm{LD}_{50}$ obtained by topical application are relatively lower, and Felton et al. (1986) suggested that the data on the acute contact and oral toxicity of pesticides to honeybees should be expressed as $\mathrm{LD}_{50}$ and should be considered as one of the elements for assessment of danger to foraging honeybees. However, our study showed that use of insecticide-impregnated papers may be better to reduce the effect on non-target species. This is critical because the honeybee genome is deficient in a number of genes encoding detoxification enzymes (Claudianos et al. 2006), therefore laboratory testing of insecticides against honey bees must guarantee exposure to the pesticides in order to avoid optimistic results.

\section{ACKNOWLEDGMENTS}

We thank Jamie Ellis and Branden Stanford (both from Entomology and Nematology Department, University of Florida, USA) for supplying A. mellifera and to the Center for Medical, Agricultural and Veterinary Entomology (CMAVE) for supplying Ae. albopictus. The research reported in this publication was supported by the Florida Department of Agriculture and Consumer Services (FDACS) under the grant fund number 025380 . The content is solely the responsibility of the authors and does not necessarily represent the official views of the FDACS.

\section{REFERENCES CITED}

Abbott WS. 1925. A method of computing the effectiveness of an insecticide. J. Econ. Entomol. 18:265-267.

Aldridge RL, Kafman PE, Bloomquist JR, Gezan SA, Linthicum KJ. 2016. Impact of topical application site on the efficacy of permetrhin and malathion to Culex quinquefasciatus. J. Am. Mosq. Control Asoc. 32:300-307.

Al Naggar Y, Codling G, Vogt A, Naiem E, Mona M, Sief Aa, Giesy JP. 2015. Organophophorous insecticides in honey, pollen and bees (Apis mellifera L.) and their potential hazard to bee colonies in Egypt. Ecotoxicology Environmental Safety. 114:1-8.

Beekman M. Ratnieks FLW. 2000. Long term foraging by the honey-bee, Apis mellifera L. Functional Ecology. 14:490:496.

Bruckner S, Steinhauer N, Rennich K, Aurell SD, Caron DM, Ellis JD, Fauvel AM, Kulhanek K, Nelson KC, Rangel J, et al. Honey Bee Colony Losses 2017-2018: Preliminary Results. Bee Informed Partnership. 2018. Available online: https://beeinformed.org/ results/honey-bee-colony-losses-2017-2018. Preliminary-results / (accessed on 13 June 2019).

Claudianos C, Ranson H, Johnson RM, Biswas S, Schuler MA, Berenbaum MR, Feyereisen R., Oakeshott JG. 2006. A deficit of detoxification enzymes: Pesticide sensitivity and environmental response in the honey bee. Insect. Mol. Biol. 15:615-636.

Danka RG, Rinderer TE, Hellmich RL, Collins AM. 1986. Comparative toxicities of four topically applied insecticides to Africanized and European honey bees (Hymenoptera: Apidae). J. Econ. Entomol. 79:18-21.

Drake LL, Gibson J. Smith M.L, Farooq M, Sallam MF, Xue, RD 2016. Evaluation of deltagard ground application against Aedes albopictus in a residential arena in St Augustine, Florida. J. Am. Mosq. Control. Assoc. 32(2):160-162.

Felton JC, Oomen PA, Stevenson JH. 1986.Toxicity and hazard of pesticides to honey bees: Harmonization of test methods. Bee World: 67:114-124.

Greig-Smith PE, Thompson HM, Hardy AR, Bew MH, Findlay E, Stevenson JH. 1994. Incidents of poisoning of honeybees (Apis mellifera) by agricultural pesticides in Great Britain 1981-1991. Crop Prot. 13 (8):567-581

Hardstone MC, Scott JG. 2010. Is Apis mellifera more sensitive to insecticides than other insects?. Pest Manag Sci: 66:1171-1180.

Inglesfield C. 1989. Pyrethroids and terrestrial non-target organisms. Pestic. Sci. 387-428.

Knox TB, Juma EO, Ochomo EO. et al. 2014. An online tool for mapping insecticide resistance in major Anopheles vectors of human malaria parasites and review of resistance status for the Afrotropical region. Parasites E् Vectors 7:76. 
López-Uribe MM. Simone-Finstrom M. 2019. Special issue: Honey bee research in the US: current state and solutions to beekeeping problems. Insects 10, 22; doi:10.3390/insects10010022.

Ostiguy N, Drummond FA, Aronstein K, Eitzer B, Ellis JD, Spivak M, Sheppard WS. 2019. Honey exposure to pesticides: a four year nationwide study. Insects. 10: 13; doi:10.3390 / insects10010013.

Qualls WA, Xue RD, Zhong H. 2010. Impact of bifenthrin on honeybees and Culex quinquefascitaus. J. Am. Mosq. Control. Assoc. 26:223-225.

WHO. 2009. Guidelines for efficacy testing of insecticides for indoor and oudoor ground-applied space spray applications. WHO/HTM/NTD/ WHOPES/2009.2. WHO. Control of Neglected
Tropical Diseases. WHO Pesticide Evaluation Scheme.

WHO. 2018. Test procedures for insecticide resistance monitoring in malaria vector mosquitoes. Second Edition. World Health Organization. ISBN 978924 1511575 (NLM classification: WA 240)

Williams GR, Tarpy DR, van Engelsdorp D, Chauzat MP, Cox-Foster DL. Delaplane KS, Neumann P, Pettis JS, Rogers REL, Shutler D. 2010. Colony collapse disorder in context. Bioassays 32. 845-846.

Zhong H, Latham M, Payne S, Brock C. 2004. Minimizing the impact of the mosquito adulticide naled on honey bees, Apis mellifera (Hymenoptera: Apidae): Aerial ultra-low-volume application using a highpressure nozzle system. J. Econ. Entomol. 97:1-7. 